\title{
ANÁLISE QUANTITATIVA E COMPARATIVA DOS MÉTODOS EXTRATIVOS SOXHLET E AGITAÇÃO MAGNÉTICA DA SCHINUS TEREBINTHIFOLIUS
}

\author{
D.R.C. TEIXEIRA ${ }^{1}$, T.R.S. NUNES ${ }^{1}$, D.C.F. VIANA ${ }^{1}$, K.T. LIRA ${ }^{1}$, H.B.S. NETO ${ }^{1}$, I.R. \\ PITTA $^{1}$ e M.R. GALDINO-PITTA ${ }^{1}$
}

${ }^{1}$ Universidade Federal de Pernambuco, Centro de Biociências, Núcleo de Pesquisa em Inovação Terapêutica Suely Galdino, Laboratório de Planejamento e Síntese de Fármacos

E-mail para contato: cravo.diego@gmail.com

RESUMO - Este trabalho objetivou analisar comparativamente diferentes métodos de extração (Soxhlet e Agitação Magnética) combinados a diferentes solventes (Água, Metanol e Etanol) quanto à eficiência na extração de metabólitos das folhas de Schinus terenbenthifolius. A extração por Soxhlet utilizando etanol como solvente se mostrou a mais eficiente, com relação à quantidade total dos picos observados no cromatograma.

Palavras chave: Aroeira da praia; plantas medicinais; HPLC; análise fatorial.

ABSTRACT - This work aim to compare different extraction methods (Soxhlet and Magnetic Stirring) combined with different solvents (Water, Methanol and Ethanol) for the extraction efficiency of Schinus terenbenthifolius metabolites. Soxhlet extraction using ethanol as solvent is the most efficient, concerning to the amount of peaks present in the chromatogram.

Keywords: Aroeira da praia; medicinal plants; HPLC; factor analysis.

\section{INTRODUÇÃO}

Schinus terebinthifolius Raddi é uma Anacardiaceae nativa do Peru. No Brasil, essa espécie se encontra distribuída em todo o litoral, e também pode ser encontrada no CentroOeste do país, estendendo-se até a Argentina e Uruguai (SCHEIBE et al., 2016). Conhecida popularmente como aroeira da praia, é considerada uma planta medicinal com propriedades de ação adstringente, balsâmica, diurética e antifúngica (SILVA et al., 2015).

A presença de metabólitos secundários, especialmente compostos fenólicos, flavonóides e terpenóides, foi descrita na literatura com potencial atividade antioxidante e antimicrobiana (ULIANA et al., 2016). Entretanto, variações das condições ambientais, fatores genéticos e estágio fisiológico da planta podem alterar os perfis da composição química de metabólitos secundários (KAWA, 2015). A composição varia bastante entre folhas de diferentes localidades e de acordo com o pré-tratamento (Gilberto \& Favoreto 2011). De 
acordo com análises químicas, o ácido gálico, pentagaloil-glucose e derivados fenólicos como o galato de metila e etila (ROSAS et al., 2015), além de flavonóides como quercetina (FEDELMIYASATO et al., 2014) são os principais componentes dos extratos hidroalcoólicos das folhas de S. terebinthifolius, conforme demonstrado na Figura 1.

Figura 1 - Derivados fenólicos como o galato de etila e metila e flavonóides como quercetina em S. terebinthifolius.

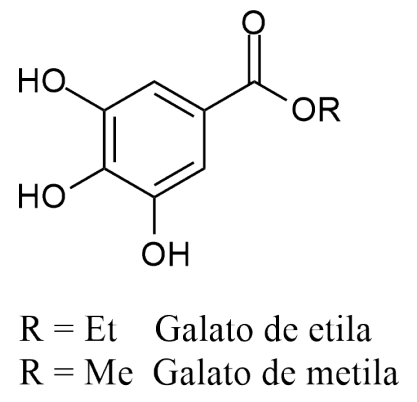<smiles>[R]c1cc(-c2oc3cc(O)cc(O)c3c(=O)c2[R])cc(O)c1O</smiles>

$\mathrm{R}=$ Ramnose; $\mathrm{Rl}=\mathrm{H}$ Quercetina

Extratos vegetais constituem misturas complexas, compostas por diversas classes de produtos naturais de diferentes grupos funcionais. O processo de extração de produtos naturais bioativos compreende separar da forma mais seletiva e completa possível, as substâncias ou fração ativa contida na droga vegetal. A escolha do método de extração é uma etapa fundamental no desenvolvimento de produtos naturais e deve considerar parâmetros de eficiência e seletividade, tais como a estabilidade dos metabólitos de interesse, o custo do processo, bem como a aplicação do extrato que se quer preparar.

A escolha do método de extração e do solvente utilizado irá depender, portanto, dos compostos de interesse, considerando-se suas características físico-químicas, como solubilidade e polaridade. Neste sentido, o objetivo do presente estudo foi analisar comparativamente diferentes métodos de extração (Soxhlet e Agitação Magnética) combinados a diferentes solventes (Água, Metanol e Etanol) quanto à efíciência na extração de metabólitos das folhas de $S$. terenbenthifolius.

\section{MATERIAIS E MÉTODOS}

\section{Coleta}

As folhas de $S$. terebinthifolius foram coletadas em julho de 2016 no Centro de Treinamento do Instituto de Pesquisa Agropecuária (CETREINO/IPA), localizado em Carpina, Pernambuco, Brasil, em condições controladas de cultivo. Após coleta, um voucher da espécie ( $n^{\circ}$ 91412) foi identificado e depositado no Herbário do IPA.

Em laboratório, as folhas foram secas em estufa por 48 horas. Em seguida, o material seco foi pulverizado.

\section{Extração}

Foram feitas três extrações por soxhlet e três extrações por agitação magnética, sendo cada extração com um tipo de solvente diferente, sendo eles água destilada, metanol 95\% e etanol 95\%. A extração por soxhlet utiliza refluxo de solvente em um processo intermitente. $\mathrm{O}$ reagente não fica em contato com o solvente. Para o presente trabalho foram feitos dois ciclos de refluxo para cada extração, utilizando um cartucho de celulose de 33 x 94mm com 
10 gramas da amostra. A agitação magnética consiste na mistura de 10 gramas da amostra pulverizada com o solvente em um becker a temperatura ambiente com agitação por 20 minutos.

\section{Experimento fatorial}

Experimentos Fatoriais, são aqueles nos quais são estudados, ao mesmo tempo, os efeitos de dois ou mais tipos de fatores ou tratamentos, onde o fator é uma variável independente cujos valores são controlados pelo experimentador. Os experimentos fatoriais consistem de todas as combinações possíveis entre os diversos fatores nos seus diferentes níveis (VIEIRA, 1999). No presente trabalho foram combinados dois métodos de extração (Soxhlet e Agitação Magnética) e três tipos de solventes utilizados na extração (Água, Metanol e Etanol), onde a combinação desses níveis leva a um total de seis experimentos (Tabela 1).

Tabela 1 - Combinação dos métodos de extração

\begin{tabular}{|c|c|c|c|}
\hline Experimentos & Água & Metanol & Etanol \\
\hline Soxhlet & A & B & C \\
\hline Agitação Magnética & D & E & F \\
\hline
\end{tabular}

\section{Cromatografia}

A Cromatografia Líquida de Alta Eficiência - CLAE foi realizada num equipamento HPLC Shimadzu® Modelo LC-20AT, tendo como fase móvel Água Milli-Q ${ }^{\circledR}$ (bomba A) e Metanol (bomba B), ambos com adição de ácido fórmico a $0,1 \%$, e fase estacionária a coluna C18 Phenomenex Synergi ${ }^{\mathrm{TM}} 4 \mu \mathrm{m}$ Fusion-RP 250 x 4,6 mm. O tempo de corrida: $70 \mathrm{~min}$; temperatura do forno: $40^{\circ} \mathrm{C}$; fluxo da fase móvel: $0,2 \mathrm{~mL} / \mathrm{min}$; tempo vs gradiente de concentração da bomba B: 0,01min - 10\% / 20min - 20\% / 30min - 30\% / 40min - 40\% / $45 \mathrm{~min}-50 \%$ / 50min - 70\% / 60min - 10\% / 70min - 10\% / $70 \mathrm{~min}$ - Stop. As amostras foram solubilizadas em metanol ou água Milli-Q ${ }^{\circledR}$ (para extratos aquosos) na diluição de $0,2 \mathrm{mg} / \mathrm{mL}$, com exceção da amostra $\mathrm{D}$, diluída para o dobro da concentração. O volume de amostra aplicado na coluna variou de 20-35 $\mu \mathrm{L}$.

\section{RESULTADOS E DISCUSSÃO}

Após a análise em HPLC das seis amostras, foram considerados os picos de área acima de 2,5\% a fim de se determinar qual o melhor método para extração de metabólitos das folhas de Schinus terenbenthifolius (Figura 2). As amostras A, B, C, D, E e F obtiveram, 6, 7, 10, 6, 7 e 6 picos de área acima de 2,5\% no cromatograma, respectivamente (Tabela 2). A amostra $\mathrm{C}$, que teve o método de extração por soxhlet e etanol como solvente se mostrou a mais eficiente devido à maior quantidade e picos no cromatograma, e ainda apresentou um pico em 34,38 min que não apareceu em nenhum dos outros cromatogramas. 
Figura 2 - Cromatogramas das amostras A, B, C, D, E, e F.
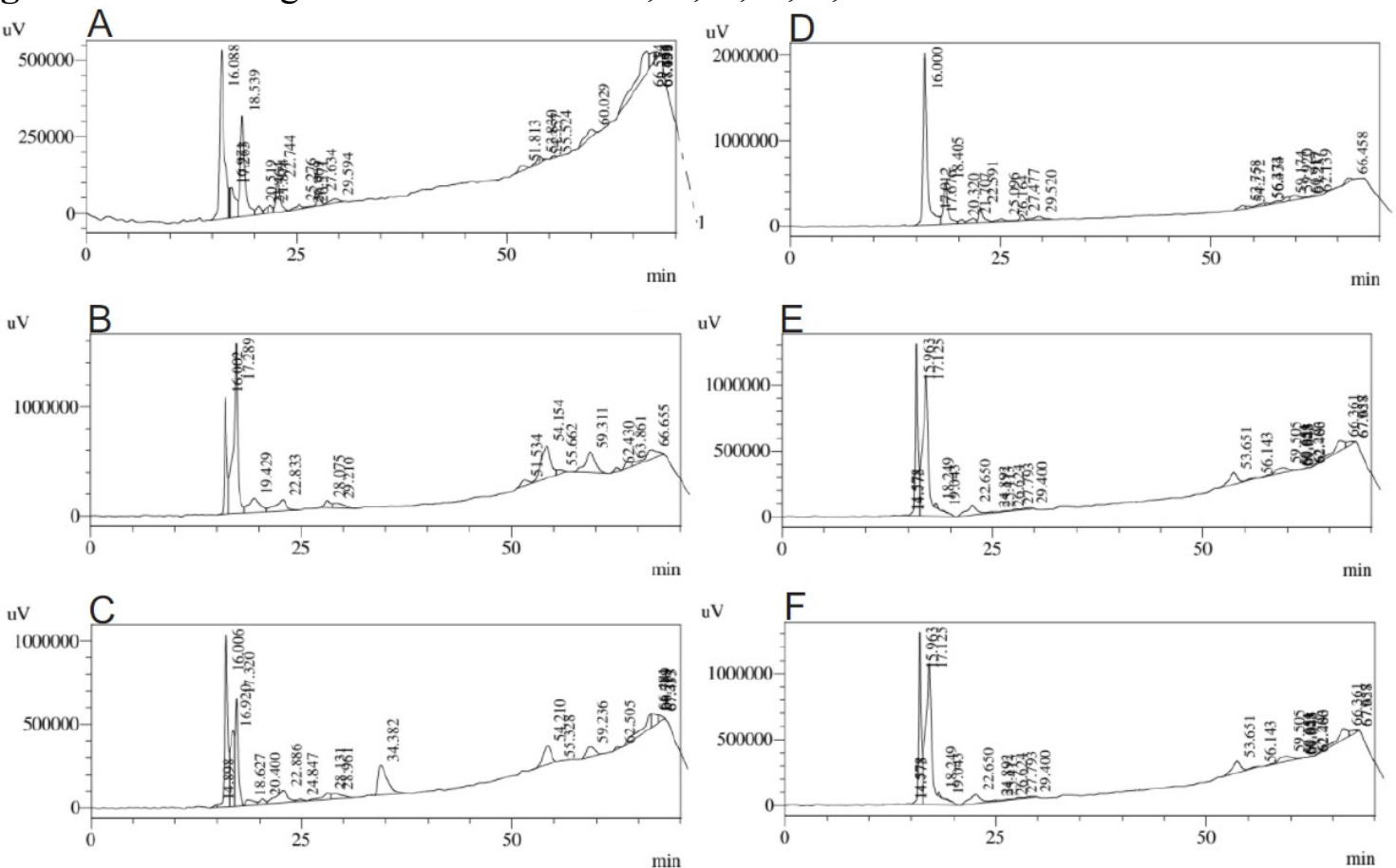

Tabela 2 - Quantidade de picos de área acima de 2,5\% obtidos por método de extração

\begin{tabular}{c|c|c|c|} 
Experimentos & Água & Metanol & Etanol \\
\hline Soxhlet & 6 & 7 & 10 \\
\hline Agitação Magnética & 6 & 7 & 6 \\
\hline
\end{tabular}

Dividindo os picos entre "Mais Polares" (0 a 35 min) e "Menos Polares" (35 a 70 min), podemos observar que o método de extração por Soxhlet e Etanol como solvente obteve a maior quantidade de picos mais polares (6) e menos polares (4). Considerando apenas a agitação magnética, o solvente metanol obteve o maior número de picos mais polares (5), enquanto o solvente etanol obteve o maior número de picos menos polares (3) (Figura 3).

Figura 3 - Gráfico da quantidade de picos das amostras, subdivididos em mais e menos polares.

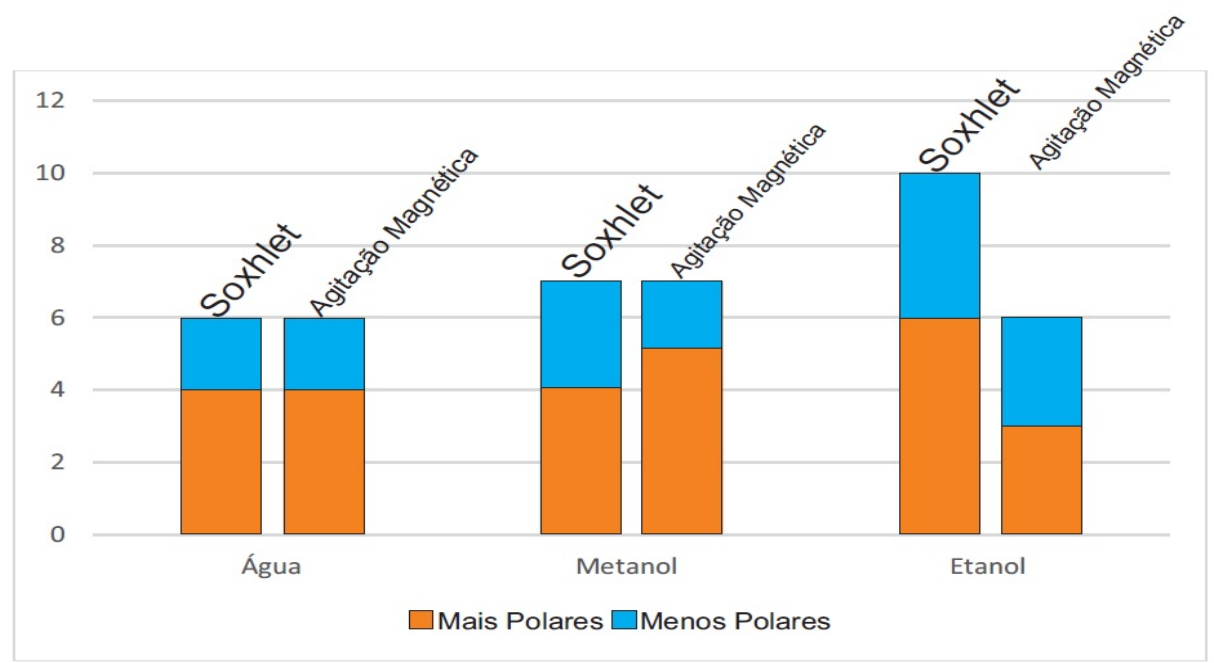




\section{CONCLUSÃO}

Considerando-se apenas o método utilizado de Agitação Magnética, o solvente mais eficiente para extração de metabólitos mais polares foi o metanol, enquanto para os menos polares, foi o etanol. Por outro lado, a extração por Soxhlet utilizando etanol como solvente se mostrou a mais eficiente com relação à quantidade total dos picos observados no cromatograma. Desta forma, a escolha do método extrativo e do solvente utilizado, considerando a polaridade dos metabólitos de interesse, figura como uma etapa determinante para futuros estudos de caracterização e atividades de Schinus terebinthifolius.

\section{REFERÊNCIAS}

FEDEL-MIYASATO, L. E. S.; FORMAGIO, A. S. N.; AUHAREK, A. S.; KASSUYA, C. A. L.; NAVARRO, S. D.; CUNHA-LAURA, A. L.; MONREAL, A. C. D.; VIEIRA, M. C.; OLIVEIRA, R. J. Antigenotoxic and antimutagenic effects of Schinus terebinthifolius Raddi in Allium cepa and Swiss mice a comparative study. Gen. Mol. Res., v. 13, p. 3411-3425, 2014.

GILBERT, Benjamin; FAVORETO, Rita. Schinus terebinthifolius Raddi. Revista Fitos, v. 6, n. 1, Dezembro 2011.

KAWA, Luciane. Schinus terebinthifolius - Aroeira vermelha. Química, Meio Ambiente e Edificações, 12 Jan. 2015.

ROSAS, E.C.; CORREA, L.B.; PÁDUA, T.A.; COSTA, T.E.M.M.; MAZZEI, J.L.; HERINGER, A.P.; BIZARRO, C.A.; KAPLAN, M.A.C.; FIGUEIREDO, M.R.; HENRIQUES, M.G. Anti-inflammatory effect of Schinus terebinthifolius Raddi hydroalcoholic extract on neutrophil migration in zymosan-induced arthritis. Journal of Ethnopharmacology, v. 175, p. 490-498, 4 December 2015.

SCHEIBE, C. L.; RIBAS-FILHO, J. M.; CZECZKO, N. G.; MALAFAIA, O.; BARBOZA, L. E. D.; RIBAS, F. M.; WENDLER, E.; TORRES, O.; LOVATO, F. C.; SCAPINI, J. G. S. Schinus terebinthifolius Raddi (Aroeira) and Orbignya phalerata mart. (Babassu) effect in cecorrahphy healing in rats. Acta Cir. Bras., v. 31, n. 6, p. 402-410, 2016.

SILVA, L.O.; OLIVEIRA, A.A.; LIMA, R.A. Identificação dos metabólitos secundários do extrato etanólico das folhas de Schinus terebinthifolius RADDI. SOUTH AMERICAN Journal of Basic Education, Technical and Technological, v. 2, n. 1, p. 84-93, 2015.

ULIANA, M.P.; FRONZA.M.; SILVA, A.G.; VARGAS, T.S.; ANDRADE, T.U.; SCHERER, R. Composition and biological activity of Brazilian rose pepper (Schinus terebinthifolius RADDI) leaves. Elsevier B.V. All rights reserved, 2015.Industrial Crops and Products, v. 83, p. 235-240, May 2016.

VIEIRA, S. Estatística experimental. 2.ed. São Paulo: Atlas: 1999. 185p

\section{AGRADECIMENTOS}

Ao LPSF, NUPIT SG, ISG, INCT-if, UFPE, FACEPE, CNPq e CAPES pela infraestrutura e pelo suporte financeiro. 